

\title{
War-related stressors are associated with asthma risk among older Kuwaitis following the 1990 Iraqi invasion and occupation
}

\author{
R J Wright, ${ }^{1,2}$ M E Fay, ${ }^{2}$ S Franco Suglia, ${ }^{2}$ C J Clark, ${ }^{2}$ J S Evans, ${ }^{2}$ D W Dockery, ${ }^{2,3}$ \\ J Behbehani ${ }^{4}$
}

${ }^{1}$ Channing Laboratory, Brigham \& Women's Hospital, Department of Medicine, Harvard Medical School; Boston, Massachusetts, USA ${ }^{2}$ Department of Environmental Health, Harvard School of Public Health, Boston, Massachusetts, USA

${ }^{3}$ Department of Epidemiology, Harvard School of Public Health, Boston, Massachusetts, USA ${ }^{4}$ Faculty of Medicine and Health Sciences, Kuwait University, Kuwait

\section{Correspondence to} Dr R J Wright, Channing Laboratory 181 Longwood Avenue, Boston, MA 02115 USA; rosalind.wright@ channing.harvard.edu

Accepted 16 September 2009 Published Online First 15 March 2010

\section{ABSTRACT}

Background Contemporary warfare involving civilian populations is a growing public health concern. In addition to the psychological impact, war-related trauma may result in physiological alterations and even broader health effects. Associations were examined between war-related stressors and incident asthma in elderly Kuwaiti civilians following the Iraqi invasion.

Methods A random sample of all Kuwaiti nationals aged 50-69 years on the day prior to the invasion were identified. Among the 7873 meeting eligibility criteria, $5567(71 \%)$ agreed to participate and 5028 completed the questionnaire ( $91 \%$ of those eligible). Of these, 3759 were in Kuwait during the invasion, of whom 2294 were alive at follow-up. After exclusions for prevalent asthma or missingness on covariates, 2066 were available for analysis. War-related experiences were summarised into a continuous score using Rasch modelling. Relative Cox proportional hazard rates (HR) were calculated for asthma adjusting for covariates.

Results Over 13 years of follow-up, physician-diagnosed asthma was reported by 66/996 (6.6\%) men and 104/ 1070 (9.7\%) women. In models adjusted for gender, socioeconomic status, smoking, BMI, and air pollution related to burning oil fires, those reporting highest stress exposure were more than twice as likely to report asthma (HR 2.3, 95\% Cl 1.3, 3.9) compared to civilians reporting no stressors. Experiences were more salient when anchored to fear for loss of life.

Conclusions War-related trauma is associated with increased asthma risk in these elderly civilians. Although prior research has documented the significant and persistent psychological toll of war, these findings implicate even broader health effects.

Contemporary warfare and political violence increasingly involves civilian populations and is a growing public health concern. ${ }^{1}$ Historically, epidemiological studies linking war-related exposures to long-term morbidity have been challenging. Often it is difficult to examine direct linkages of the original war-related experiences, given that most populations in this circumstance experience prolonged periods of armed conflict. Moreover, after the conflict, most endure prolonged economic crisis, lack of stable social systems and ongoing deprivation or displacement, which may continue to impact health. ${ }^{2}$

The Kuwait experience provides a unique research opportunity for many reasons. The invasion of Kuwait in 1990 was followed by a 7-monthlong Iraqi occupation. Although the period between the invasion and liberation was relatively short compared to most conflicts, and many Kuwaiti civilians were out of the country at the time of the invasion and occupation, many remained and endured harsh conditions and fear of harm. ${ }^{3}$ At least 15000 were arrested and approximately 1000 were killed. After liberation, Kuwaitis did not live in exile for long periods and the physical and social infrastructure was restored in a comparatively short time. ${ }^{4}$

Although epidemiologists are beginning to examine the long-term health effects of such experiences in population-based studies, the literature has largely focused on persistent psychological co-morbidities including depression, anxiety, and post-traumatic stress disorder (PTSD). ${ }^{5} 6$ Although such emotional states may represent adaptive functioning in the face of trauma, they may exact a toll on mental as well as physical health for years to come.

In addition to having significant psychological impact, war-related trauma may result in physiological alterations that lead to even broader health effects, a notion grounded in traumatic stress theory. ${ }^{17}$ In general, stressors are thought to influence the pathogenesis of disease by causing negative affective states (eg anxiety, depression, and PTSD), which in turn exert effects on biological processes or behavioural patterns that influence disease risk. ${ }^{8}$ When environmental demands are perceived to be threatening and exceed one's abilities to cope, or when one feels that events are unpredictable or that one has no control, individuals experience stress.

Many aspects of the Iraqi invasion and subsequent occupation fit this paradigm. Traumatic experiences, including living in fear, separation from family, exposure to shelling or combat, witnessing or being a victim of violence or torture, displacement, witnessing arrests of others, and sexual assault have been documented. ${ }^{4}{ }^{6}$ Arbitrary acts of oppression or violence by Iraqi soldiers had Kuwaiti civilians living in constant fear of potential harm, torture, sexual assault and other atrocities. $^{39}{ }^{9}$ In the context of a natural disaster, the persistence of psychological distress symptoms has been related to collapse of community infrastructure. ${ }^{1}$ Destruction of the physical infrastructure may have further predisposed this population to chronic psychological trauma. ${ }^{4}$ Thus, the traumatic stress paradigm linking psychological stress and affective states to disruption of key physiological mechanisms, and ultimately to 
disease expression, provides a framework for plausible mechanisms linking war-related trauma, psychological functioning and physical health. ${ }^{7}$

Asthma provides a disease paradigm for examining this posited link. Efforts to understand the role of stress in asthma expression have expanded in the context of an increased understanding of the overlap between the neurobiology of stress and asthma pathophysiology. ${ }^{10}$ Psychological stressors and negative emotional responses disturb the regulation of the sympathetic and adrenomedullary (SAM) system and the hypothalamic-pituitary-adrenocortical (HPA) axis - physiological systems may operate at higher or lower levels than during normal homeostasis. The detrimental cost of such accommodation has been conceptualised as allostatic load (ie chronic underor over-activity of the allostatic system). ${ }^{11}$ Hormones and neuropeptides released into the circulation when individuals experience stress regulate both immune-mediated and neurogenic inflammatory processes. Altered neuroimmune responses may influence the expression of immune-mediated or inflammatory disorders in particular, including asthma. Moreover, the authors' group has previously demonstrated a link between asthma and caregiving stress ${ }^{12}$ and other traumatic stressors (ie domestic violence). ${ }^{13} 14$

Although an individual's reaction to trauma is multifaceted and associated with a range of psychological sequelae, in the context of extreme events (eg war) distress symptoms associated with PTSD (eg chronic re-experiencing of the trauma) have been most widely studied. ${ }^{5}$ Because war-related experiences are outside the range of usual human experience and almost universally distressful, they are more likely to lead to PTSD. In turn, PTSD has been linked to disruption of stress pathways even several years following the experienced trauma, ${ }^{15}$ as well as being linked prospectively to increased mortality ${ }^{16}$ and chronic disease risk ${ }^{17}$ in veterans. Amongst Cambodian ${ }^{18}$ and Bosnian $^{19}$ refugees, researchers have shown a dose-response (cumulative) relationship in which incremental exposure to a variety of adverse events was associated with increasing risk of PTSD. ${ }^{18}$ Moreover, the significance and meanings underlying trauma experiences may be more important than discrete events in determining psychological functioning and other adverse health risk. Specifically, fear of loss of life in the context of trauma has emerged as a particularly salient precipitant of subsequent morbidity. ${ }^{20} 21$

The relationship between war-related trauma and physical health has not been examined in non-refugee civilian populations experiencing such conflict. Here, associations were examined between war-related stressors and incident asthma in older adult Kuwaitis following the invasion and occupation. It was hypothesised that among Kuwaiti civilians who remained in the country, those experiencing greater cumulative stressors would be at increased risk for asthma compared to those with lesser exposure. Finally, fear for loss of life anchored to war experiences was considered as a modifier.

\section{METHODS}

The Public Authority for Civil Information provided the base population of all Kuwaiti nationals (ages 50-69 years) alive on the day before invasion (1 August 1990). In order to get a random sample who were either in or out of Kuwait during the invasion, subjects were matched to Ministry of Finance records of Kuwaitis receiving a stipend ( US \$1500) for remaining in Kuwait during the entire occupation. A random representative sample of 7873 Kuwaitis was selected. Subjects were initially contacted by phone and then written consent was obtained during face-to-face interviews conducted in homes between December 2003 and January 2005. The questionnaire confirmed location (in or out of Kuwait) and ascertained information on war-related experiences, sociodemographics, smoking, height and weight, and asthma. Of 7873 subjects, 5567 (71\%) agreed to participate; 5028 successfully completed the survey. Analyses were restricted to those in Kuwait during the occupation (3759/ 5028) and therefore at risk for exposure to trauma; of these, 2294 were alive at the time of the survey. Finally, 228 were excluded because of prevalent asthma or missing values on covariates, leaving 2066 for analyses.

\section{War-related stressors}

Assessing war-related trauma in epidemiological research is challenging. At the time of this survey, there were no empirically developed measures of war-related events in civilian, non-refugee populations. ${ }^{22}$ Determining which events are most relevant to risk of PTSD and other health sequelae is complex, given that civilians exposed to war typically experience multiple traumas, some of which are relatively universal and some that may be unique to a particular setting. The present survey was based on the Harvard Trauma Questionnaire, developed from refugees in clinical samples. ${ }^{23}$ This was supplemented through interviews with individuals from the relevant population to capture events specific to the Kuwaiti experience. ${ }^{6}$

Another challenge is creating a predictor that is not directly measured, but is ascertained through multiple items related to the exposure (eg war-related traumatic events). ${ }^{24}$ An approach previously applied to quantifying exposure to community violence was adapted. ${ }^{25}$ Rasch modelling, a form of latent variable analysis, summarises dichotomous responses to the multi-item questionnaire into a continuous score on the logit scale. A continuous measure is obtained by modelling the conditional probability of responding "yes" to each item given the extremity or severity of each question. For example, when a subject with low exposure is asked whether a severe form of trauma was experienced, the expected probability of endorsement is low. Latent variable models also allow us to account for information that may modify the impact of the event [eg frequency of events and characteristics of the perpetrator and victim (stranger vs non-stranger)]. ${ }^{25}$ Subjects reported whether they directly experienced and/or had witnessed various events. The Rasch model assigns weights for the severity of the events experienced assuming events endorsed less frequently are more severe. In such a scale with both witness and victimisation items, witnessed events would be considered less severe as they were reported more frequently than victimisation. To accommodate this, a model using both witness and victimization items was implemented, creating two scales but taking into account the existing correlation between the scales. ${ }^{26} \mathrm{~A}$ War-Related Stressor Score (WRSS) was defined as the average of the two continuous scales, that is, the latent variable of exposure to both witnessed events and victimization. These models were implemented using logistic non-linear mixed models (proc NLMIXED) in SAS 9.0 (SAS Institute, Cary, NC, USA).

\section{Asthma}

Asthma was determined by the question "Have you ever been told by a doctor that you have asthma?", with a follow-up to determine the year they received the diagnosis, a standard approach with demonstrated reliability. ${ }^{27}$ Incident asthma was defined as being diagnosed following the date of liberation (27 February 1991). 


\section{Covariates}

Analyses were adjusted for age, gender, and social status including education and literacy. Age on the date of invasion was categorised as 50-54, 55-59, 60-64, and 65-69 years. Challenges to defining social status in this older age cohort ${ }^{28}$ and in the Kuwaiti culture were considered. ${ }^{29}$ For example, Arab elders often rely on assistance solely from family members and would not be expected to report income of their own. ${ }^{30}$ Data were available on education level and literacy, which have been associated with differential health risks in the Gulf region. ${ }^{31}$ Education was dichotomised as never attending school or attending school at any level. Smoking was defined as "never", "former", or "current". Body mass index (BMI) was calculated based on self-reported weight and height (weight in kilograms divided by the square of height in metres) and entered as a continuous measure. Self-reported weight and height are acceptably correlated with measured weight and height in the elderly. ${ }^{32}$ Air pollution from burning oil fires, an environmental contaminant from the war potentially related to asthma, ${ }^{33} 34$ was also controlled. Daily exposure to oil fire fine particulate matter $\left(2.5 \mu \mathrm{m}, \mathrm{PM}_{2.5}\right)$ (modelled to account for area of residence, climate factors, etc, using CalPUFF dispersion models ${ }^{35}$ ) was averaged over the time subjects reported being in Kuwait during the invasion up to 6 November 1991 when the last fire was extinguished, ${ }^{36}$ and entered as a continuous indicator [mean oil fire $\mathrm{PM}_{2.5}\left(\mu \mathrm{g} / \mathrm{m}^{3}\right)$ ]. And finally, it was considered whether an individual reported fear for loss of life in the context of reported traumas as a modifier of the relationship between war-related experiences and asthma.

\section{Analysis}

Crude morbidity rates were calculated as the number of subjects reporting doctor-diagnosed asthma divided by the number within each WRSS exposure level. To assess for a dose-response, the trauma score was categorised as no trauma compared to the Rasch scale divided into tertiles [low $(-1.0$ to -0.2$)$, intermediate $(-0.2$ to 0.7$)$ and high $(0.7$ to 3.8$)]$. Time to incidence was calculated as the reported year of diagnosis (or year of interview for those without asthma) minus date of liberation. Relative Cox proportional hazard rates (HR) were calculated adjusting for covariates. Asthma risk was considered based on war-related stressor level and whether subjects experienced fear for loss of life related to events during the Iraqi occupation, which may potentiate post-trauma morbidity. ${ }^{19}$ Analyses were conducted using SAS version 9 (SAS Institute; Cary, NC, USA).

\section{RESULTS}

Mean age (58.7 \pm 5.6 and 58.2 \pm 5.5 , men and women respectively) and BMI $(26.7 \pm 4.7$ and $28.8 \pm 5.8$, men and women respectively) were similar across gender. Significant differences were seen for literacy (72.2\% men; $29.8 \%$ women), any education (54.1\% men; $16.0 \%$ women) and smoking status (non-smoker $41.6 \%$ and $84.3 \%$; former smoker $37.2 \%$ and $9.0 \%$; and current smoker $21.3 \%$ and $6.7 \%$, men and women respectively). Education and literacy levels were low in this older sample, having historically had less opportunity for education. ${ }^{37}$ Table 1 details the distribution of covariates relative to asthma diagnosis. In addition, BMI was higher among those with asthma (28.7 \pm 6.3$)$ compared to non-asthmatics $(27.7 \pm 5.3)(p=0.02)$; mean oil fire $\mathrm{PM}_{2.5}$ was not significantly different between asthmatics and non-asthmatics $[55.8 \pm 15.8$ vs $50.4 \pm 15.9 \mu \mathrm{g} / \mathrm{m}^{3}$ respectively $(\mathrm{p}=0.8)$ ]. Table 2 depicts frequencies of war-related stressors included in the Rasch model; 368 reported no trauma [154 men (16\%), 214 women $(20 \%)]$. More than half of the men (68\%) and women $(59 \%)$ feared for loss of life. The WRSS (figure 1) can be interpreted in a relative sense (eg -0.5 represents lower exposure than a score of 2.0). Among 413 with a score $<-0.75$, only one reported assault, three were arrested and 28 reported having their house searched; none witnessed torture, rape or executions. In contrast, among 517 with a score $>0.85,12 \%$ were arrested, $16 \%$ assaulted and $57 \%$ witnessed torture.

Incident asthma was reported by $66 / 996(6.6 \%)$ men and $104 / 1070$ (9.7\%) women. In univariate analyses, there was a direct relationship between higher level exposure on the WRSS ( $p$ for trend 0.0003) and asthma risk (data not shown), with the highest tertile predicting a doubling of asthma risk (HR 2.0; 95\% CI 1.2 to 3.2). Adjusting for covariates did not significantly change this relationship (HR 2.3; 95\% CI 1.3 to 3.9) (table 3).

The elevated risk for asthma was most evident in the subgroup reporting fear for loss of life associated with the highest WRSS level (table 4), albeit a formal test of an interaction was not statistically significant $(p=0.12)$, likely in part due to small cell sizes.

\section{DISCUSSION}

War-related stressors were associated with elevated risk of incident asthma in elderly Kuwaiti civilians exposed to the 1990 Iraqi invasion adjusting for other war-related environmental contaminants (air pollution from the burning oil fires), social status, BMI and smoking. Although prior research has documented the significant and persistent psychological toll of such experiences, these findings implicate even broader health effects. The suggested dose-response relationship parallels studies demonstrating cumulative effects of war-related trauma on psychological health, eg incremental increases in exposure to war-related events among Bosnian refugees was associated with increasing risk of PTSD. ${ }^{19}$

There was also a suggestion that trauma exposure was more salient when it was anchored to fear for loss of life. The significance and meanings underlying trauma experiences may be more important than discrete events in determining PTSD and other adverse health risk. ${ }^{38} 39$ These studies show that life threat is salient to triggering PTSD in Western cultures, a finding recently corroborated in populations with more diverse religious and cultural backgrounds (eg Bosnian Muslim refugees). ${ }^{19}$ Dahl and colleagues ${ }^{40}$ found a higher rate of PTSD among Bosnian women who had been threatened with death than those with general war experiences. In the present data, the suggestion that experiences were more salient when anchored to fear for loss of life is consistent with the higher rates of psychological morbidity reported among these Bosnian women threatened with death. ${ }^{40}$

Future studies examining the long-term effects of war-related stressors on civilians should be designed to more formally test whether these relationships are mediated through adverse psychological sequelae (eg PTSD) and consequential physiological disruption. ${ }^{41}$ Research incorporating such multimodal assessments of the response to war-related experiences will be most informative. For example, prospective studies should examine alterations of stress axes (eg HPA axis, SAM system) linked to PTSD and other psychological sequelae resulting from war experiences that, in turn, play a role in disease expression. Future research should also consider differential gender effects female gender is a risk factor for PTSD in general and studies of war-related trauma report higher levels of distress in women 
Table 1 Distribution of covariates based on asthma diagnosis

\begin{tabular}{|c|c|c|c|}
\hline \multirow[b]{2}{*}{ Covariates } & \multirow[b]{2}{*}{ Total } & \multirow{2}{*}{$\frac{\text { New asthma }}{\mathbf{N}(\%)}$} & \multirow[b]{2}{*}{ p Value* } \\
\hline & & & \\
\hline \multicolumn{4}{|c|}{ War-Related Trauma Score } \\
\hline No reported trauma & 368 & $23(6.3)$ & \multirow[t]{4}{*}{0.001} \\
\hline Low & 573 & $35(6.1)$ & \\
\hline Medium & 571 & $45(7.9)$ & \\
\hline High & 554 & $67(12.1)$ & \\
\hline \multicolumn{4}{|l|}{ Sex } \\
\hline Male & 996 & $66(6.6)$ & \multirow[t]{2}{*}{0.01} \\
\hline Female & 1070 & $104(9.7)$ & \\
\hline \multicolumn{4}{|l|}{ Age } \\
\hline $50-54$ & 679 & $51(7.5)$ & \multirow[t]{4}{*}{0.73} \\
\hline $55-59$ & 574 & $53(9.2)$ & \\
\hline $60-64$ & 467 & $37(7.9)$ & \\
\hline $65-69$ & 346 & $29(8.4)$ & \\
\hline \multicolumn{4}{|l|}{ Education } \\
\hline No & 1356 & $116(8.6)$ & \multirow[t]{2}{*}{0.46} \\
\hline Yes & 710 & $54(7.6)$ & \\
\hline \multicolumn{4}{|l|}{ Literacy } \\
\hline No & 1028 & $101(9.8)$ & \multirow[t]{2}{*}{0.009} \\
\hline Yes & 1038 & $69(6.7)$ & \\
\hline \multicolumn{4}{|l|}{ Smoking } \\
\hline Non-smoker & 1316 & $107(8.1)$ & \multirow[t]{3}{*}{0.86} \\
\hline Ex-smoker & 466 & $41(8.8)$ & \\
\hline Current & 284 & $22(7.8)$ & \\
\hline \multicolumn{4}{|l|}{ Fear loss of life } \\
\hline No & 778 & $56(7.2)$ & \multirow[t]{2}{*}{0.18} \\
\hline Yes & 1284 & $114(8.9)$ & \\
\hline
\end{tabular}

compared to men, as well as differences related to contextual factors (eg the impact of fear for loss of life). ${ }^{15} 19$

Although the study has strengths given the large sample and the unique circumstances related to the invasion and occupation, some limitations are also noted. Self-reported physician- diagnosed asthma was used, which has been validated in other research albeit not in Kuwaiti populations. ${ }^{42}$ The prevalence of asthma in Kuwait as well as other Persian Gulf states appears to be similar to that in industrialised or Western countries. ${ }^{43} 44 \mathrm{~A}$ number of factors related to asthma diagnosis in this older

Table 2 War-related experiences*

\begin{tabular}{|c|c|c|c|}
\hline War-related experiences & $\frac{\text { All (N = 2066) }}{n(\%)}$ & $\frac{\text { Men }(n=996)}{n(\%)}$ & $\begin{array}{l}\text { Women }(n=1070) \\
N(\%)\end{array}$ \\
\hline \multicolumn{4}{|l|}{ Witnessed events } \\
\hline Health threat due to lack of financial/medical support & $471(22.8)$ & $250(25.1)$ & $221(20.6)$ \\
\hline Family arrested & $661(32)$ & $313(31.4)$ & $348(32.5)$ \\
\hline Family rape & $21(1.0)$ & $9(0.9)$ & $12(1.1)$ \\
\hline Family shot & $244(11.8)$ & $106(10.6)$ & $138(12.9)$ \\
\hline Family torture & $217(10.5)$ & $97(9.7)$ & $120(11.2)$ \\
\hline Other rape* & $51(2.5)$ & $32(3.2)$ & $19(1.8)$ \\
\hline Other torture* & $283(13.7)$ & $171(17.2)$ & $112(11)$ \\
\hline Other assault* & $309(15.0)$ & $196(19.7)$ & $113(11)$ \\
\hline Execution* & $241(11.7)$ & $157(15.8)$ & $84(7.9)$ \\
\hline House searched ${ }^{*}$ & $1242(60.1)$ & $661(66.4)$ & $581(54.3)$ \\
\hline House loss/destroyed ${ }^{*}$ & $532(25.8)$ & $279(28)$ & $253(23.6)$ \\
\hline \multicolumn{4}{|l|}{ Direct victimisation } \\
\hline Assaulted at checkpoint ${ }^{*}$ & $57(2.8)$ & $42(4.2)$ & $15(1.4)$ \\
\hline Assaulted at demonstration & $14(0.7)$ & $10(1.0)$ & $4(0.4)$ \\
\hline Assaulted somewhere else ${ }^{*}$ & $64(3.1)$ & $49(5.0)$ & $15(1.4)$ \\
\hline Tortured* & $32(1.5)$ & $27(0.7)$ & $5(0.5)$ \\
\hline Sexually assaulted or raped & $9(0.4)$ & $4(0.4)$ & $5(0.5)$ \\
\hline House searched & $1142(55.3)$ & $564(56.6)$ & $578(54)$ \\
\hline House loss/destroyed ${ }^{*}$ & $328(15.9)$ & $141(14.2)$ & $187(17.5)$ \\
\hline Arrested* & $86(4.2)$ & $81(8.1)$ & $5(0.5)$ \\
\hline In hiding* & 288 (13.9) & $121(12.1)$ & $167(15.6)$ \\
\hline
\end{tabular}

*Denotes significant differences between men and women based on $\chi^{2} \mathrm{p}$ value $<0.05$. 


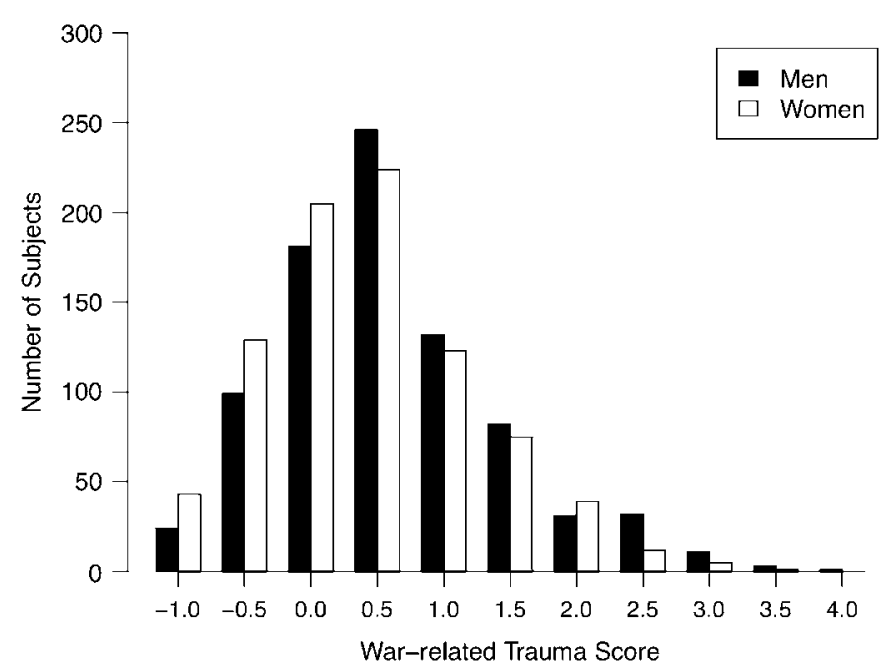

Figure 1 Rasch scores on the logit scale for those reporting any warrelated stressors summarised in table 2.

Kuwaiti adult population are corroborated by studies from the West ${ }^{45} 46$ as well as the region. ${ }^{47}$ It was found that the number of new cases of asthma was higher among women consistent with existing prevalence and incidence studies, ${ }^{47}$ as well as a suggestion of increased risk for former smokers. ${ }^{48}$ In this population of older adults there is also the possibility of overreporting of asthma due to confusion with reporting chronic obstructive pulmonary disease (eg emphysema or chronic bronchitis). This is only biased to the extent that such overreporting is correlated with our main exposure, war-related trauma, which seems unlikely. It also seems unlikely that associations might represent trauma leading to acute exacerbations of existing undiagnosed subclinical asthma, as the majority (81\%) of incident cases were diagnosed a year or more

Table 3 War-Related Stressor Score and asthma incidence: adjusted model

\begin{tabular}{|c|c|}
\hline & HR $(95 \% \mathrm{Cl})^{*}$ \\
\hline \multicolumn{2}{|c|}{ War-Related Stressor Score } \\
\hline No reported stressors & Ref \\
\hline Low & $1.0(0.6$ to 1.8$)$ \\
\hline Intermediate & $1.4(0.8$ to 2.4$)$ \\
\hline High & $2.3(1.3$ to 3.9$)$ \\
\hline \multicolumn{2}{|l|}{ Gender } \\
\hline Male & Ref \\
\hline Female & $1.4(1.0$ to 2.4$)$ \\
\hline \multicolumn{2}{|l|}{ Age at invasion } \\
\hline $50-54$ & Ref \\
\hline $55-59$ & $1.3(0.9$ to 2.1$)$ \\
\hline $60-64$ & $1.1(0.7$ to 1.8$)$ \\
\hline $65-69$ & $1.4(0.9$ to 2.4$)$ \\
\hline \multicolumn{2}{|l|}{ Education } \\
\hline No & Ref \\
\hline Yes & $1.9(1.1$ to 3.3$)$ \\
\hline \multicolumn{2}{|l|}{ Literacy } \\
\hline Yes & Ref \\
\hline No & 1.9 (1.1 to 3.2$)$ \\
\hline \multicolumn{2}{|l|}{ Smoking } \\
\hline Non-smoker & Ref \\
\hline Ex-smoker & $1.3(0.9$ to 2.0$)$ \\
\hline Current & $1.1(0.7$ to 1.9$)$ \\
\hline BMI (per SD change) & $1.0(0.9$ to 1.2$)$ \\
\hline Mean oil fire $\mathbf{P M}_{2.5}$ & $1.0(0.99$ to 1.0$)$ \\
\hline
\end{tabular}

*Hazard rate ( $95 \%$ confidence interval).
Table 4 Asthma risk by stressor level and fear for loss of life ${ }^{*}$

\begin{tabular}{ll}
\hline & $\begin{array}{l}\mathbf{N}=\mathbf{2 0 6 6} \\
\mathbf{H R}(\mathbf{9 5 \%} \mathbf{C I}) \dagger\end{array}$ \\
\hline $\begin{array}{l}\text { Fear loss of life } \\
\text { No reported stressors }\end{array}$ & $0.7(0.3$ to 1.7$)$ \\
Low & $0.7(0.4$ to 1.5$)$ \\
Intermediate & $1.4(0.7$ to 2.7$)$ \\
High & $2.0(1.1$ to 3.6$)$ \\
No fear loss of life & \\
No reported stressors & Ref $(-)$ \\
Low & $1.1(0.5$ to 2.2$)$ \\
Intermediate & $0.8(0.4$ to 1.7$)$ \\
High & $1.3(0.6$ to 2.8$)$ \\
\hline *Adjusted for age, gender, education, literacy, smoking, BMl and mean oil fire $\mathrm{PM}_{2.5}$. \\
†Hazard rate and 95\% confidence interval.
\end{tabular}

after the invasion. Also, socioeconomic status may be related to access to healthcare, differential exposure to war trauma, type of housing and other environmental factors that also may contribute to asthma risk. Although adjusting for education and literacy did not change the observed associations, characterisation of socioeconomic status in this sample is notably complex, ${ }^{28} 29$ and residual confounding may remain. Another possible explanation for the findings is that individuals with psychological morbidity related to trauma experiences may be more likely to seek medical attention or over-report medical complaints. ${ }^{49}$ Follow-up studies should systematically assess psychological co-morbidities and incorporate objective measures of the asthma outcome (eg airway responsiveness, lung function, asthma medication use, immunophenotyping). The study may also have been strengthened through the inclusion of personal monitoring of air pollution exposures rather than prediction modelling, albeit this information was not available in this dataset.

\section{What is already known on this subject}

- Contemporary warfare increasingly involving civilians is a growing public health concern.

- Although epidemiologists are beginning to examine the longterm health effects of war-related experiences, research to date has largely focused on persistent psychological sequelae or on cardiovascular disease.

- War-related trauma may result in physiological disruptions that may result in even broader health effects.

\section{What this study adds}

- This is the first study to find associations between war-related trauma and chronic respiratory disease, namely asthma risk among elderly civilians exposed to war.

- Research linking war-related stressors to long-term physical health expands our understanding of the full scope of the health effects of war.

- Recognising and intervening around psychological difficulties related to war experiences early in the course may diminish the risk of developing non-psychiatric sequelae in the long run. 
In summary, evidence was found that increased war-related trauma is associated with elevated risk of new-onset asthma in elderly Kuwaiti civilians exposed to the Iraqi invasion and occupation. Although prior research has documented the significant and persistent psychological toll of such trauma, these findings implicate even broader health effects. Recognising and intervening around psychological co-morbidities related to trauma early in the course may diminish the risk of developing non-psychiatric sequelae related to such experiences, thus further research in this area is warranted. ${ }^{49}$

Acknowledgements We are grateful to Dr. Wajh Sawaya and Professor Zoran Radovanovic. We thank Kadhema Scientific Consultancy who conducted interviews and Temple University Institute for Survey Research for designing and implementing the sampling, data collection, and data entry. We appreciate the cooperation of the Kuwait Ministry of Finance and the Public Authority for Civil Information. Most importantly we thank the Kuwaiti families. This study does not necessarily represent the official position of the State of Kuwait nor the Public Authority for the Assessment of Compensation from the Iraqi Aggression.

Dedication We dedicate this paper to the memory of our dear colleague, Professor Jaafar Behbehani of the Kuwait University Faculty of Medicine, who was the inspiration for this work. Jaafar's vision; his personal and professional understanding of the impacts of war on the physical and mental well-being of civilian populations; his untiring dedication and devotion to develop the scientific evidence needed to inform this matter; and his personal elegance and warmth made this work possible. We owe him a great debt and hope that the publication of this paper will in some small way ensure that his contributions to science are appreciated.

Funding This study was funded by the Public Authority for Assessment of Compensation for Damage Resulting from the Iraqi Aggression.

Competing interests None

Ethics approval Study procedures were approved by the Kuwait University Faculty of Medicine and Harvard School of Public Human Studies Committees.

Provenance and Peer review Not commissioned; externally peer reviewed.

\section{REFERENCES}

1. Pederson D. Political violence, ethnic conflict, and contemporary wars: broad implications for health and social well-being. Soc Sci Med 2002;55:175-90.

2. Miller KE, Weine SM, Ramic A, et al. The relative contribution of war experiences and exile-related stressors to levels of psychological distress among Bosnian refugees. J Traumatic Stress 2002;15:377-87.

3. Kalin W. Report on the situation of human rights in Kuwait under Iraqi occupation: Special Rapparteur of the Commission on Human Rights in accordance with Commission resolution 1991/67; E/CN.4/1992/26. 1992.

4. Feighery TJ. Assessing the costs of Iraq's 1990 invasion and occupation of Kuwait the United Nations Compensation Commission. Refugee Survey Quarterly 2003;22:87-104

5. Johnson $\mathbf{H}$, Thompson A. The development and maintenance of post-traumatic stress disorder (PTSD) in civilian adult survivors of war trauma and torture: A review. Clin Psychol Rev 2008;28:36-47.

6. Staehr AA, Staehr MA, Behbehani J, et al. Treatment of war victims in the Middle East: International Rehabilitation Council for Torture Victims. Copenhagen: IRCT, 1993.

7. Christopher M. A broader view of trauma: A biopsychosocial-evolutionary view of the role of the traumatic stress response in the emergence of pathology and/or growth. Clin Psychol Rev 2004;24:75-98.

8. Cohen S, Janicki-Deverts D, Miller GE. Psychological stress and disease. J Am Med Assoc 2007;298:1685-7.

9. Bernhard WN, Barish R, Al-ibrahim MS, et al. War crimes during the Persian Gulf War. Military Med 1992;157:667-9.

10. Wright RJ. Stress and atopic disorders. J Allergy Clin Immunol 2005;116:1301-6.

11. McEwen BS. Protective and damaging effects of stress mediators: the good and bad sides of the response to stress. Metabolism: Clin Exp 2002:51:2-4.

12. Wright RJ, Cohen S, Carey V, et al. Parental stress as a predictor of wheezing in infancy: A prospective birth-cohort study. Am J Resp Crit Care Med 2002;165:358-65.

13. Subramanian SV, Ackerson LK, Subramanyam MA, et al. Domestic violence is associated with adult and childhood asthma prevalence in India. Int J Epidemiol 2007;36:569-79

14. Suglia SF, Enlow MB, Kullowatz A, et al. Maternal intimate partner violence and increased asthma incidence in children: buffering effects of supportive caregiving Arch Pediatr Adolescent Med 2009:163:244-50.

15. Tolin DF, Foa EB. Sex differences in trauma and posttraumatic stress disorder: a quantitative review of 25 years of research. Psycholog Bull 2006;132:959-92.

16. Johnson DR, Fontana $\mathrm{A}$, Lubin $\mathrm{H}$, et al. Long-term course of treatment-seeking Vietnam veterans with posttraumatic stress disorder: mortality, clinical condition, and life satisfaction. J Nervous Mental Dis 2004;192:35-41.
17. Kubzansky LD, Koenen KC, Spiro A, et al. Prospective study of posttraumatic stress disorder symptoms and coronary heart disease in the Normative Aging Study. Arch Gen Psych 2007;64:109-16.

18. Mollica RF, McInnes K, Poole C, et al. Dose-effect relationships of trauma to symptoms of depression and post-traumatic stress disorder among Cambodian survivors of mass violence. Br J Psych 1998;173:482-8.

19. Momartin S, Silove D, Manicavasagar V, et al. Dimensions of trauma associated with posttraumatic stress disorder (PTSD) caseness, severity and functional impairment: a study of Bosnian refugees resettled in Australia. Soc Sci Med 2003:57:775-81.

20. Blaszcynski A, Gordon K, Silove D, et al. Psychiatric morbidity following motor vehicle accidents: a review of methodological issues. Comprehensive Psych 1998;39:111-21.

21. McFarlane AC. The aetiology of posttraumatic morbidity: predisposing, precipitating and perpetuating factors. Br J Psych 1989;154:221-8.

22. Hollifield $\mathbf{M}$, Warner TD, Lian $\mathbf{N}$, et al. Measuring trauma and health status in refugees: a critical review. J Am Med Assoc 2002;288:611-21.

23. Mollica RF, Caspi-Yavin Y, Bolini $P$, et al. The Harvard Trauma Questionnaire: Validating a cross-cultural instrument for measuring torture, trauma and posttraumatic stress disorder in Indochinese refugees. J Nervous Mental Dis 1992;180:111-16.

24. Cunny KA, Perri M. Single-item vs. multiple-item measures of health-related quality of life. Psycholog Rep 1991;69:127-30.

25. Suglia SF, Ryan L, Wright RJ. Creation of a community violence exposure scale: accounting for what, who, where, and how often. J Traumatic Stress 2008:21:479-86.

26. Horton NJ, Laird NM, Zahner GEP. Use of multiple informant data as a predictor of psychiatric epidemiology. Int J Methods Psych Res 1999;8:6-18.

27. Pattaro C, Locatelli F, Sunyer J, et al. Using the age at onset may increase the reliability of longitudinal asthma assessment. J Clin Epidemiol 2007;60:704-11.

28. Grundy $\mathbf{E}$, Holt $\mathrm{G}$. The socioeconomic status of older adults: How should we measure it in studies of health inequalities? J Epidemiol Community Health 2001;55:895-904.

29. Shah NM, Shah MA, Radovanovic Z. Towards defining socioeconomic and demographic inequalities that may affect health in Kuwait. Medical Principles Practice 1998; 7:33-46.

30. Ajrouch KJ. Resources and well-being among Arab-American elders. J CrossCultural Gerontol 2007:22:167-82.

31. Boutayeb A, Serghini M. Health indicators and human development in the Arab region. Int J Health Geographics 2006;5:61-73.

32. Gunnell D, Berney L, Holland P, et al. How accurately are height, weight and leg length reported by the elderly and how closely are they related to measurements recorded in childhood? Int J Epidemiol 2000;29:456-64.

33. Rostker B. Environmental exposure report: Oil well fires. Department of Defense (USA). http://www.gulflink.osd.mil/oil well fires/index.html, 1998.

34. Samet JA, Holquin F. Asthma and air quality. Curr Opin Pulmonary Med 2007; 13:63-6.

35. Scire JS, Strimaitis DG, Yamartino RJ. A User's Guide for the CALPUFF Model: Earth Tech, Inc.

36. Wilson AM, Eschenroeder A0, Evans JS. Final Human Health Risk Assessment: Mortality risks from oil fire particulate matter exposure. Deliverable HD 3.1c(ii-f)/ 4.2d(ii-f) HD 2.3/2.4. Boston, MA: Harvard School of Public Health, 2005.

37. Meleis AF, El-Sanabary N, Beeson D. Women, modernization, and education in Kuwait. Comparative Education Rev 1979;23:115-24.

38. Morgan CA, Hazlett G, Wang S, et al. Symptoms of dissociation in humans experiencing acute, uncontrollable stress: a prospective investigation. Am J Psych 2001:158:1239-47.

39. Silove D. The psychological effects of torture, mass human rights violations and refugee trauma: toward an integrated conceptual framework. J Nervous Mental Dis 1999:187:200-7.

40. Dahl S, Mutapoic A, Schei B. Traumatic events and predictive factors for posttraumatic symptoms in displaced Bosnian women in a war zone. J Traumatic Stress 1998;11:137-45

41. Wessa M, Rohleder N. Endocrine and inflammatory alterations in post-traumatic stress disorder. Exp Rev Endocrinol Metabolism 2007:2:91-122.

42. Jenkins MA, Clarke JR, Carlin JB, et al. Validation of questionnaire and bronchial hyperresponsiveness against respiratory physician assessment in the diagnosis of asthma. Int J Epidemiol 1996;25:609-16.

43. Bener A, Abdulrazzaq YM, DeBusse $P$, et al. Prevalence of asthma among Emirates school children. Eur J Epidemiol 1994;10:271-8.

44. Al-Mousawi MSH, Lovel H, Behbehani N, et al. Asthma and sensitization in a community with low indoor allergen levels and low pet-keeping frequency. J Allergy Clin Immunol 2004:114:1389-94.

45. DeMarco R, Lfacatelli F, Sunyer J, et al. Differences in incidence of reported asthma related to age in men and women: a retrospective analysis of the data of the European Respiratory Health Study. Am J Resp Crit Care Med 2000:162:68-79.

46. Eagan TM, Brogger JC, Elide GE, et al. The incidence of adult asthma: a review. Int J Tuberculosis Lung Dis 2005:9:603-12.

47. Hamzacebi H, Unsal M, Kayhan S, et al. Prevalence of asthma and respiratory symptoms by age, gender and smoking behaviour in Samsun, North Anatolia Turkey. Tuberkuloz ve Toraks Dengisi 2006;54:322-9.

48. Eisner MD. Smoking and adult asthma: a healthy smoker effect? Am J Resp Crit Care Med 2002;165:1566-7.

49. Weisberg RB, Bruce SE, Machan JT, et al. Nonpsychiatric illness among primary care patients with trauma histories and posttraumatic stress disorder. Psychiatr Serv 2002; 53:848-54 